\title{
ANALISA FAKTOR-FAKTOR YANG PALING DOMINAN PENYEBAB KETERLAMBATAN PROYEK
}

\author{
Yovantianus V. Nabut, Sebastianus B. Henong, Agustinus H. Pattiraja. \\ 1,2,3 Program Studi Teknik Sipil, Fakultas Teknik, Universitas Katolik Widya Mandira Kupang \\ Email : sebasthenong00@gmail.com
}

\begin{abstract}
ABSTRAK
Pembangunan proyek konstruksi di kabupaten kupang saat ini mengalami perkembangan yang sangat pesat banyak gedung dan jalan raya yang dibangun guna mengakomodir kebutuhan masyarakat. Penelitian ini menitikberatkan pada faktor-faktor penyebab keterlambatan yang terjadi pada proyek pembangunan Monumen Flobamora Rumah Pancasila. Penelitian ini diselesaikan menggunakan kuisioner yang disebar kepada para pihak yang terlibat langsung dalam proses pembangunan monumen flobamora rumah Pancasila. Hasil penelitian menemukan 5 faktor yang mempunyai nilai importance index teratas yakni: kurangnya pengalaman kerja tukang $(68,41 \%)$, pengaruh cuaca hujan $(66,90 \%)$, terlambatnya pengiriman peralatan ke lokasi proyek (52,36\%),kurangnya pengalaman kerja pengawas lapangan $(43,63 \%)$, keterlambatan pembayaran oleh owner $(32,29 \%)$. Rekomendasi yang diberikan berdasarkan keterlambatan yang terjadi pada proyek pembangunan monumen flobamora rumah pancasila yakni kurangnya pengalaman kerja tukang, Meningkatkan pengawasan terhadap para tukang dengan menambah tenaga kepala pekerja dan mandor. Pengaruh cuaca hujan, sebaiknya lebih sering diberlakukan jam lembur saat kondisi cuaca tidak hujan agar produksi yang berkurang akibat terjadinya hujan dapat ditanggulangi, kurangnya pengalaman kerja pengawas lapangan, melakukan pendampingan dan pengarahan bagi para pengawas lapangan yang kurang berpegalaman.
\end{abstract}

Kata kunci : Proyek, Konstruksi, Keterlambatan, Monumen Flobamora Rumah Pancasila

\begin{abstract}
ABSTRAC
The construction of construction projects in Kupang district is currently experiencing a very rapid development, many buildings and roads were built to accommodate the needs of the community. This research focuses on the factors that cause delays that occur in the construction project of the Pancasila Flobamora Monument. This research was completed using a questionnaire distributed to parties directly involved in the process of building the Flobamora monument of the Pancasila house. The results of the study found 5 factors that have the highest importance index value, namely: lack of work experience of masons $(68.41 \%)$, the influence of rainy weather $(66.90 \%)$, late delivery of equipment to the project location (52.36\%), lack of work experience. field supervisors (43.63\%), late payments by the owner (32.29\%). Recommendations given are based on the delay that occurred in the construction project of the Pancasila flobamora monument, namely the lack of work experience of masons, Increasing supervision of the masons by increasing the workforce of the head of workers and foremen. The influence of rainy weather, it is better if overtime hours are applied when the weather conditions are not raining so that reduced production due to rain can be overcome, the lack of work experience of field supervisors, providing assistance and direction for less experienced field supervisors.
\end{abstract}


Vol 2 No 2 (2021), July 2021, pp. 1-9

(C2021 Jurnal Teknik Sipil Cendekia

Doi : https://doi.org/10.51988/jtsc.v2i2.33

\section{PENDAHULUAN}

Proyek Konstruksi merupakan salah satu bentuk kegiatan yang berlangsung dalam waktu yang terbatas dan menggunakan sumber daya serta biaya yang telah diperhitungkan, untuk mencapai hasil dalam bentuk bangunan atau infrastruktur. Dalam pelaksanaan proyek konstruksi melibatkan penyedia jasa (kontraktor dan konsultan) dan pemilik proyek (owner) yang saling terkait dalam sebuah ikatan perjanjian kerja yang disebut kontrak. Proyek konstruksi dikatakan berhasil jika penyedia jasa berhasil melaksanakan pembanguan proyek sesuai waktu, biaya dan mutu yang ditetapkan dalam dokumen kontrak. Keterlambatan proyek konstruksi pada prinsipnya akan menyebabkan kerugian bagi pihak-pihak terkait terutama pemilik dan kontraktor, karena umumnya disertai konflik, tuntutan waktu dan biaya, serta penyimpangan kualitas penyelesaian proyek. (Saleh, 2005). Kerugian yang dialami oleh pemilik yakni kehilangan opportunity karena proyek belum bisa menghasilkan profit, sedangkan kerugian yang dialami oleh kontraktor adalah dikenai sanksi. Bagi proyek pemerintah, misalnya pada proyek rumah sakit, maka kerugian akan mengarah pada kerugian non-materil seperti tertundanya penggunaan ruang operasi yang sifatnya urgent sehingga pasien harus dirujuk ke rumah sakit lain.Ada berbagai macam alasan yang dikeluhkan para kontraktor antara lain keterlambatan pengiriman bahan material dikarenakan cuaca yang buruk, para pekerja kurang berpengalaman dan para pekerja kurang berpengetahuan. Pembangunan monument Flobamora Pancasila Kota Kupang pun mengalami keterlambatan. Berdasarkan data yang diperoleh dari lapangan, proyek ini terkendala beberapa alasan antara lain tukang kurang berpengalaman, pengiriman material yang terhambat dan cuaca kurang bersahabat. Tujuan dari penelitian ini yakni mau mengetahui factor-faktor apa saja yang paling berpengaruh terhadap keterlambatan yang terjadi pada proyek pembangunan Monumen Flobamora Rumah Pancasila.

\section{METODE}

Penelitian ini diselesaikan dengan metode analysis frekuensi sederhana. Dimana dengan terlebih peneliti menyebar kuesioner kepada para pelaku yang terlibat dalam pembangunan Monumen Flobamora Rumah Pancasila antara lain para tukang, konsultan perencana, konsultan pengawas dan kontraktor. Data yang terkumpul di lapangan melalui kuisioner akan dianalisis dengan menggunakan teknik statistik sebagaimana diuraikan berikut ini:

\section{Frequency index}

Girsang dalam Henong (2016) mengemukakan bahwa frequency index adalah salah satu formula yang digunakan untuk mengukur seberapa sering faktor-faktor penyebab terjadinya keterlambatan proyek berdasarkan frekuensi terjadinya (frequency index). Semakin besar nilai frequency index maka peringkatnya akan semakin kecil. Frequency index dapat dihitung dengan rumus sebagai berikut :

$$
\mathrm{FI}(\%)=\sum_{j=1}^{5} a x\left(\begin{array}{l}
n \\
N
\end{array}\right) \times 100 / 5
$$

Dimana: $\quad$ FI $=$ Frequency index

$$
\begin{aligned}
& \mathrm{a}=\text { Bobot tiap penilaian } \\
& \mathrm{n}=\text { Jumlah responden yang memilih tiap penilaian } \\
& \mathrm{N}=\text { Jumlah total responden }
\end{aligned}
$$

\section{Severity index}

Girsang dalam Henong (2016) mengemukakan bahwa severity index merupakan suatu formula yang dipergunakan untuk peringkat dari setiap faktor-faktor penyebab keterlambatan proyek 
Vol 2 No 2 (2021), July 2021, pp. 1-9

(C2021 Jurnal Teknik Sipil Cendekia

Doi : $\underline{\text { https://doi.org/10.51988/itsc.v2i2.33 }}$

berdasarkan dampak atau keburukan yang diakibatkan. Semakin besar nilai severity index maka peringkatnya akan semakin kecil. Severity index dapat dihitung dengan rumus sebasgai berikut:

$\mathrm{SI}(\%)=\sum_{j=1}^{n 5}\left(a x \frac{n}{N} \times 100 / 5\right)$

Dimana : $\quad \mathrm{Si}=$ Saverity index

$\mathrm{a}=$ Bobot tiap penilaian

$\mathrm{n}=$ Jumlah responden yang memilih tiap penilaian

$\mathrm{N}=$ Jumlah total responden

Importance index

Girsang dalam Henong (2016) mengemukakan bahwa importance index merupakan suatu formula yang dipergunakan untuk mengetahui peringkat dari setiap faktor-faktor penyebab keterlambatan proyek berdasarkan gabungan antara frequency index dan severity index. Semakin besar importance index maka peringkatnya akan semakin kecil. Importance index dapat dihitung dengan formula sebagai berikut :

$$
\begin{aligned}
& \text { IMPI }(\%)=\{\text { FI }(\%) \times \text { SI }(\%) / 100 \ldots \ldots \ldots . . . \\
& \text { Diamana : } \text { IMPI = Impotance index }(\%) \\
& \text { FI = Frequency index }(\%) \\
& \text { SI }=\text { Saverity index }(\%)
\end{aligned}
$$

\section{ANALISIS DAN PEMBAHASAN}

\section{Analisis}

\section{Frequency Index}

Berdasarakan hasil perhitungan terdapat tiga factor yang mempengaruhi, yang mempunyai frekuensi diatas $75 \%$. Berdasarkan presepsi responden terdapat tiga faktor yang menduduki peringkat teratas seberapa sering terjadinya (Frequency Of Occurrence) adalah :

1. Terlambatnya pengiriman peralatan ke lokasi proyek $=87,27 \%$

2. Cuaca hujan $=83,63$

3. Kurangnya pengalaman kerja tukang $=81,81 \%$

Tiga faktor yang menduduki peringkat terbawah adalah :

1. Izin kerja $=32,72 \%$

2. Kurangnya pengaaman kerja mandor $=41,81 \%$

3. Kerusakan bahan material di tempat penyimpanan $=43,63 \%$

Penjabaran hasil perhitungan secara lengkap dapat dilihat pada grafik di bawah ini 
Vol 2 No 2 (2021), July 2021, pp. 1-9

(C2021 Jurnal Teknik Sipil Cendekia

Doi : https://doi.org/10.51988/jtsc.v2i2.33

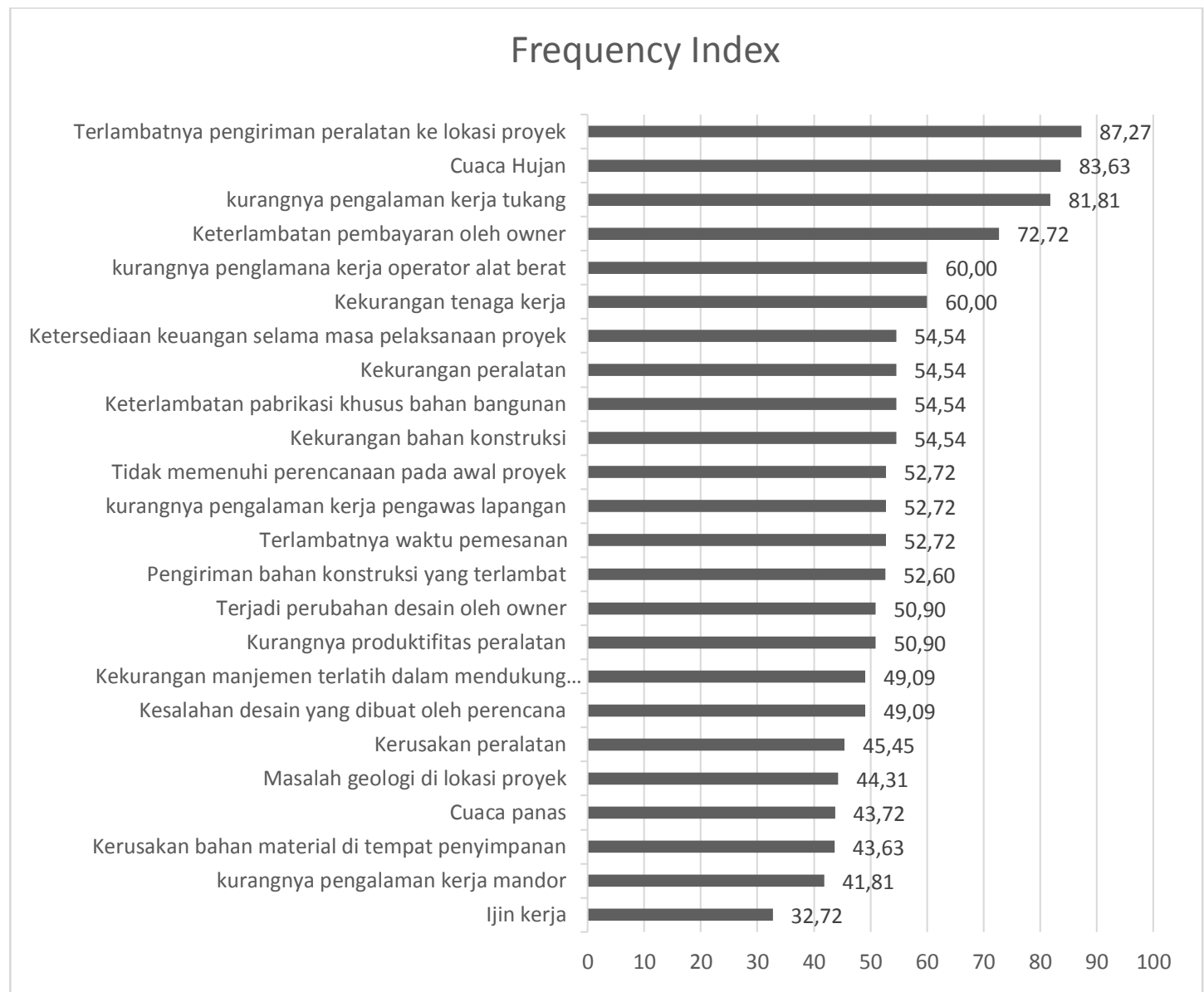

Sumber: Hasil Analisis

Gambar 2: Peringkat Faktor-Faktor Penyebab Keterlambatan Pada proyek Pembangunan Monumen Flonbamora Rumah Pancasila Berdasarkan Frequency Index

\section{Saverity Index}

Dari hasil perhitungan secara umum terdapat tiga faktor yang mempunyai severity index diatas $70 \%$. Berdasrkan presepsi responden terdapat tiga faktor yang menduduki peringkat teratas seberapa besar dampak terjadinya (severity of occurance) adalah :

1. Kurangnya pengalaman kerja tukang $=83,63 \%$

2. Cuaca hujan $=80,00 \%$

3. Kuarangnya pengalaman kerja pengawaws lapangan $=74,54 \%$

Sedangkan tiga faktor yang memberi dampak terkecil sehingga menyebabkan terjadinya keterlambatan pada Pembangunan Monumen flobamora Rumah Pancasila adalah :

1. Kurangnya pengalaman kerja operator alat berat $=38,18 \%$

2. Masalah geologi di lokasi proyek $=38,21 \%$

3. Kerusakan bahan material di tempat pnyimpanan $=40,00 \%$

Penjabaran hasil perhitungan secara lengkap dapat dilihat pada grafik di bawah ini : 
Vol 2 No 2 (2021), July 2021, pp. 1-9

(C)2021 Jurnal Teknik Sipil Cendekia

Doi : https://doi.org/10.51988/itsc.v2i2.33

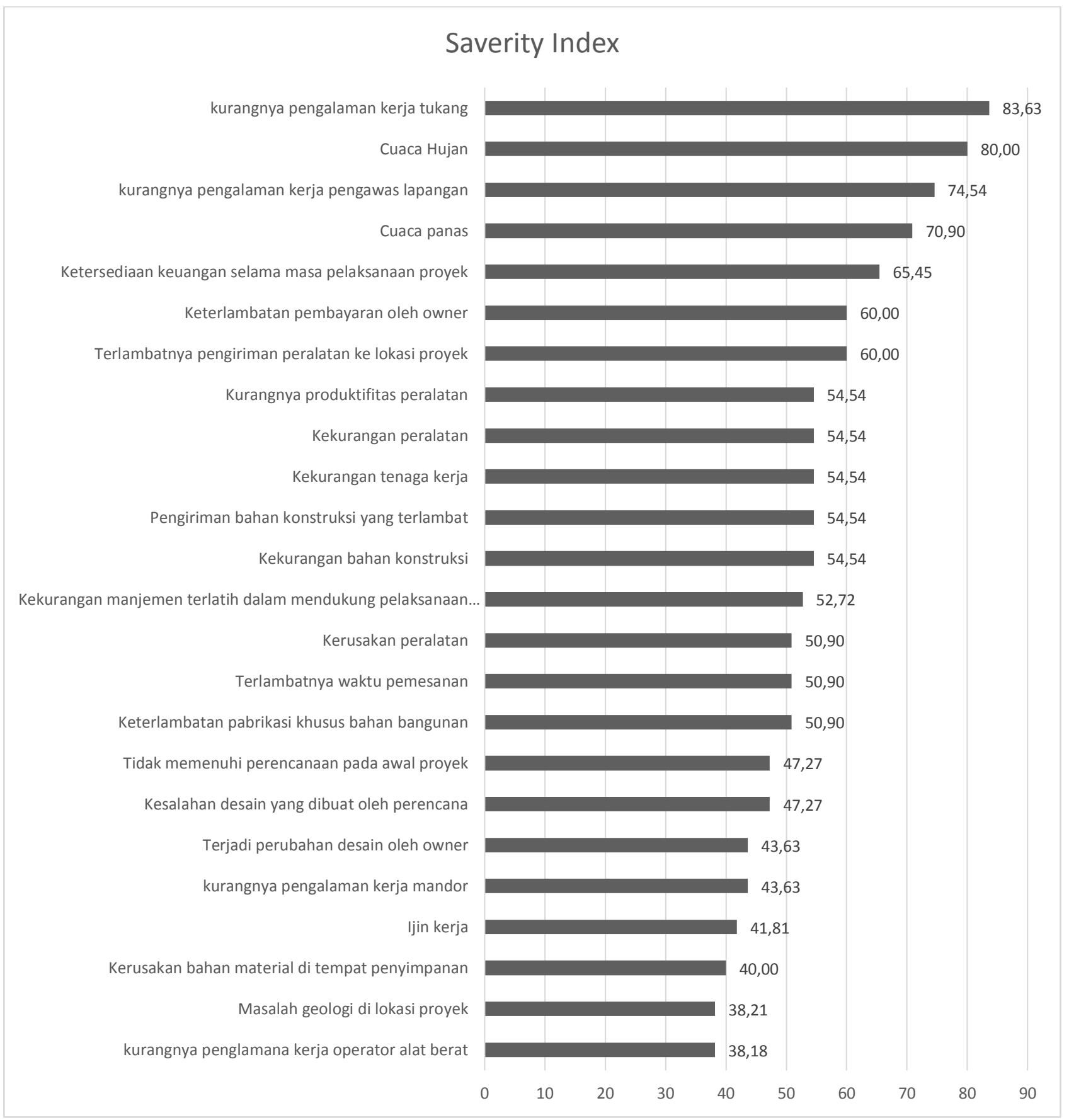

Sumber: Hasil Analisis

Gambar 3: Peringkat Faktor-Faktor Penyebab Keterlambatan Pada Proyek Pembangunan Monumen Flobamora Rumah Pancasila Berdasarkan Saverity Index 
Vol 2 No 2 (2021), July 2021, pp. 1-9

(C)2021 Jurnal Teknik Sipil Cendekia

Doi : https://doi.org/10.51988/jtsc.v2i2.33

\section{Importance index}

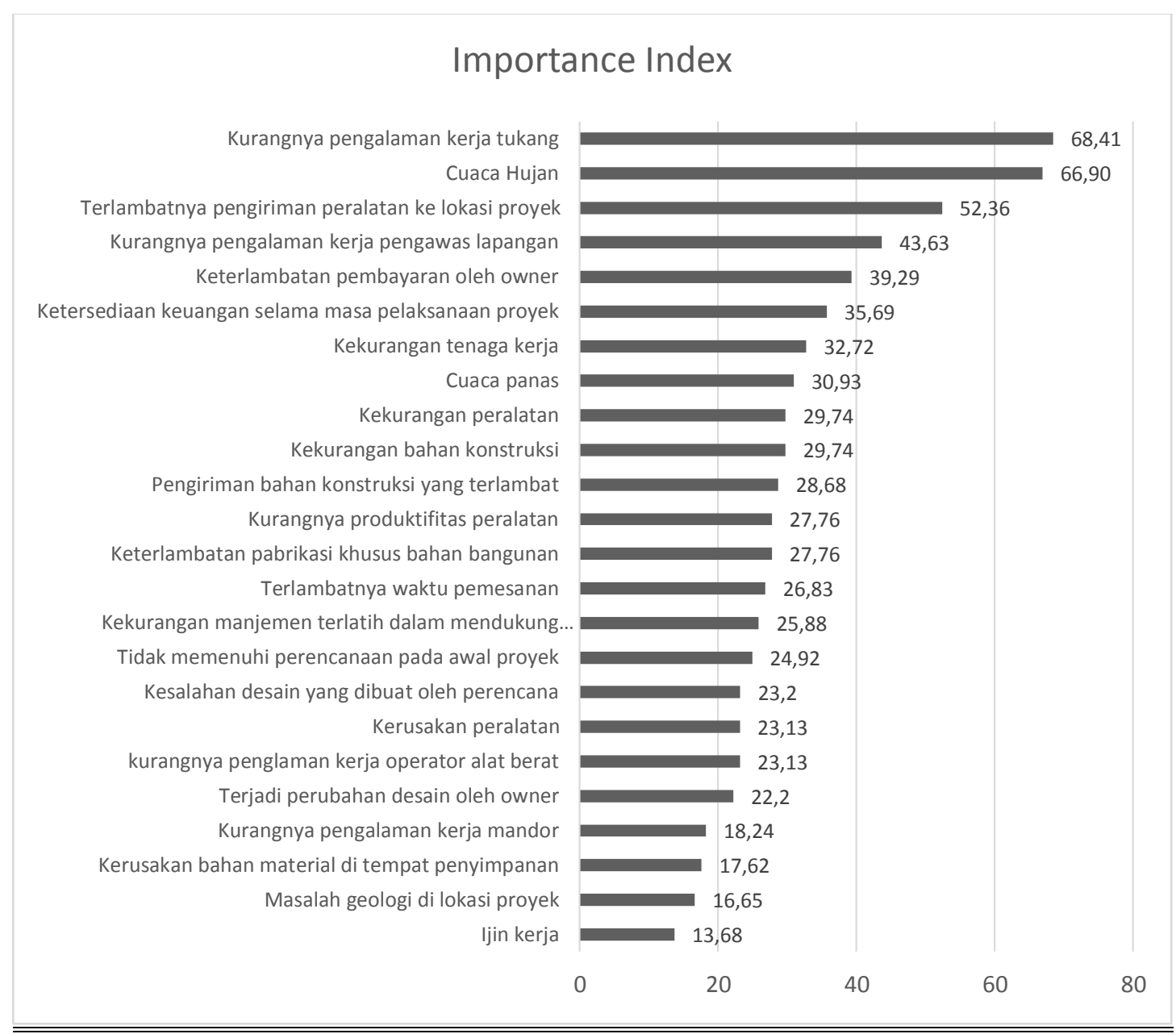

Sumber: Hasil Analisis

Gambar 4: Peringkat Faktor-Faktor Penyebab Keterlambatan Pada Proyek Pembangunan Monumen Flobamora Rumah Pancasila Berdasarkan Importance Index

Berdasarkan Importance Index yaitu hasil perkalian antara Frequency Index dan Saverity Index didapat 5 faktor yang paling penting yang menjadi penyebab keterlambatan pada proyek Pembangunan Monumen Flobamora Rumah Pancasila adalah:

1. Kurangnya pengalaman kerja tukang $(68,41 \%)$

Hasil perkalian antara frequency index dan saverity index menenmpatkan faktor ini sebagai faktor yang penting penyebeb keterlambatan pada Pembangunan Monumen Flobamora Rumah Pancasila.

2. Cuaca hujan $(66,90 \%)$

Hasil perkalian antara frequency index dan severity index menempatkan faktor ini sebagai salah satu faktor yang paling penting yang menjadi penyebab keterlambatan yang terjadi pada Pembangunan Monumen Flobamora Rumah Pancasila.

3. Terlambatnya pengiriman peralatan ke lokasi proyek $(52,36 \%)$ 
Vol 2 No 2 (2021), July 2021, pp. 1-9

(C)2021 Jurnal Teknik Sipil Cendekia

Doi : $\underline{\text { https://doi.org/10.51988/itsc.v2i2.33 }}$

Peralatan merupakan salah satu sumber daya penting dalam pelaksanaan penyelesaian proyek guna mempercepat dan membantu pekerjaan, terlambatnya pengiriman alat berat di lokasi proyek, peralatan dalam pembahasan ini dikhususkan pada Tower Crane.

4. Kurangnya pengalaman kerja pengawas lapangan $(43,63)$

Skala untuk menentukan tingkat prosentase faktor kurangnya pengalaman kerja pengawas lapangan yakni pada seluruh item pekerjaan yang dikerjakan di lapangan karena seorang pengawas lapangan bertanggung jawab pada semua pekerjaan yang ada di lapangan.

5. Keterlambatan pembayaran oleh owner $(39,29 \%)$

Pendanaan dalam suatu proyek biasanya berasal dari pemilik proyek saja tapi dalam pelaksanaan proyek di lapangan pendanaan bisa berasal dari dua sumber yaitu langsung dari pemilik proyek atau dari modal kontraktor dulu, bisa pula gabungan dari keduanya.

\section{PEMBAHASAN}

Pembangunan Monumen Flobamora Rumah Pancasila, setelah melalui analisis ditemukan alasanalasan :

a. Keterlambatan antara lain karena kurang pengalaman tukang. Hal ini memang dibenarkan karena untuk mencari tukang-tukang yang benar-benar professional sangat susah. Karena itu peran mandor serta pengawas lapngan sangat diharapkan untuk mencoba membantu para tukang dalam menyelesaikan proses pembangunan.

b. Cuaca yang buruk. Cuaca yang buruk merupakan kejadian diluar kendali. Karena itu para pekerja diminta agar bisa lembur menggantikan cuaca yang buruk.

c. Terlambat pengiriman peralatan ke lokasi proyek. Peralatan merupakan salah satu sumber daya penting dalam pelaksanaan penyelesaian proyek guna mempercepat dan membantu pekerjaan, terlambatnya pengiriman alat berat di lokasi proyek, peralatan dalam pembahasan ini dikhususkan pada Tower Crane. Karena tinggi total bangunan Monumen Pancasila menurut rencana adalah $45 \mathrm{~m}$ (sampai jambul garuda), akan tetapi dalam perlaksanaan pengerjaan menggunakan Mobile Crane. Oleh karena itu hasil perkalian antara frequency index dan severity index menempatkan faktor ini sebagai salah satu faktor yang penting penyebab keteralambatan yang terjadi pada Pembangunan Monumen Flobamora Rumah Pancasila.

d. Kurangnya penglaman kerja pengawas. Skala untuk menentukan tingkat prosentase faktor kurangnya pengalaman kerja pengawas lapangan yakni pada seluruh item pekerjaan yang dikerjakan di lapangan karena seorang pengawas lapangan bertanggung jawab pada semua pekerjaan yang ada di lapangan. Dikarenakan kurangnya pengalaman kerja seorang pengawas dapat mempengaruhi seluruh aspek pembnagunan. Sehingga banyak terjadi kesalahan-kesalahan pekerjaan konstruksi.

e. Keterlambatan pembayaran oleh owner. Pendanaan dalam suatu proyek biasanya berasal dari pemilik proyek saja tapi dalam pelaksanaan proyek di lapangan pendanaan bisa berasal dari dua sumber yaitu langsung dari pemilik proyek atau dari modal kontraktor dulu, bisa pula gabungan dari keduanya. Karena owner terlambat membayar maka pekerjaan menjadi terhambat. 
Vol 2 No 2 (2021), July 2021, pp. 1-9

(C2021 Jurnal Teknik Sipil Cendekia

Doi : https://doi.org/10.51988/jtsc.v2i2.33

\section{KESIMPULAN}

1. Dari hasil penelitian yang dilakukan dapat disimpulkan bahwa faktor-faktor penyebab keterlambatan yang paling dominan terjadi pada proyek Pembangunan Monumen Flobamora Rumah Pancasila antara lain : Kurangnya pengalaman kerja tukang $(68,41 \%)$, pengaruh cuaca hujan $(66,90 \%)$, terlambatnya pengiriman peralatan ke lokasi proyek $(52,36 \%)$, kurangnya pengalaman kerja pengawas lapangan $(43,63 \%)$, keterlambatan pembayaran oleh owner $(39,29 \%)$, ketersediaan keuangan selama masa pelaksanaan proyek $(35,69 \%)$, kekurangan tenaga kerja $(32,72 \%)$, pengaruh cuaca panas $(30,93 \%)$, kekurangan peralatan $(29,74 \%)$, kekurangan bahan konstruksi $(29,74 \%)$, pengiriman bahan konstruksi yang terlambat $(28,68 \%)$, kurangnya produktifitas peralatan $(27,76 \%)$, keterlambatan pabrikasi khusus bahan bangunan $(27,76 \%)$, terlambatnya pemesanan bahan konstruksi $(26,83 \%)$, kekurangan manajemen terlatih dallam mendukung pelaksanaan proyek $(25,88 \%)$, tidak memenuhi perencanaan pada awal proyek (24,92\%), kesalahan desain yang dibuat oleh perencana $(23,20 \%)$, kerusakan peralatan $(23,13 \%)$, kurangnya pengalaman kerja operator alat berat $(23,13 \%)$, terjadi perubahan desain oleh owner $(22,20 \%)$, kurangnya pengalaman kerja mandor $(18,24 \%)$, kerusakan bahan material di tempat penyimpanan $(17,62 \%)$, masalah geologi di lokasi proyek (16,65\%), izin kerja $(13,68 \%)$.

2. Berdasarkan importance index dan hasil wawancara di lokasi penelitian maka diidentifikasi 5 faktor paling dominan yang menjadi penyebab keterlambatan yang terjadi pada Pembangunan Monumen Flobamora Rumah pancasila antara lain: Kurangnya pengalaman kerja tukang $(68,41 \%)$, pengaruh cuaca hujan $(66,90 \%)$, terlambatnya pengiriman peralatan ke lokasi proyek $(52,36 \%)$, kurangnya pengalaman kerja pengawas lapangan $(43,63 \%)$, keterlambatan pembayaran oleh owner $(39,29 \%)$

3. Rekomendasi yang diberikan berdasarkan hasil penelitian terhadap keterlambatan yang terjadi pada Pembangunan Monumen Flobamora Rumah Pancasila antara lain :

a. Kurangnya pengalaman kerja tukang, tukang merupakan sumberdaya yang penting dalam pelaksanaan pengerjaan proyek gedung oleh karena itu hal ini perlu diberi perhatian lebih, perhatian yang dimaksud antara lain dengan cara: Meningkatkan pengawasan terhadap para tukang dengan menambah tenaga kepala pekerja dan mandor, para pengawas lapangan perlu meningkatkan kontrol terhadap kerja para tukang dan melakukan pendampingan bagi para tukang, memperketat kualifikasi agar para tukang dapat bekerja sesuai dengan kemampuan dan keahliannya.

b. Pengaruh cuaca hujan, sebaiknya lebih sering diberlakukan jam lembur saat kondisi cuaca tidak hujan agar produksi yang berkurang akibat terjadinya hujan dapat ditanggulangi, sebaiknya masa pelaksanaan proyek dijadwalkan tidak saat musim hujan.

c. Terlambatnya pengiriman peralatan ke lokasi proyek, pihak kontraktor dan manajemen harus bisa menjadwalkan peralatan tiba di lokasi proyek sesuai dengan time schedule bilaperlu peralatan sudah ada sebelum proyek dimulai,

d. Kurangnya pengalaman kerja pengawas lapangan, seorang pengawas lapangan bertanggung jawab pada semua pekerjaan yang ada di lapangan sesuai dengan spesifikasi oleh karena itu hal ini perlu diberikan perhatian khusus jika menginginkan proyek tepat waktu, tepat mutu dan tepat biaya. Perhatian khusus yang dapat diberikan antara lain: Melakukan pendampingan dan pengarahan bagi para pengawas lapangan yang kurang berpegalaman, meningkatkan komunikasi yang baik dengan pengawas lapangan lain di lokasi proyek yang lebih senior agar bisa berbagi ilmu dan pengetahuan 
Vol 2 No 2 (2021), July 2021, pp. 1-9

(C2021 Jurnal Teknik Sipil Cendekia

Doi : https://doi.org/10.51988/itsc.v2i2.33

e. Keterlambatan pembayaran oleh owner, Pelaksanaan pembangunan proyek konstruksi membutuhkan biaya terus menerus sepanjang waktu pelaksanaannya hingga selesai, keterlambatan pembayaran oleh owner akan sangat mempengaruhi kelancaran pekerjaan dan akan berdampak pada keterlambatan oleh oleh karena itu sebaiknya kontraktor perlu menyediakan dana sementara ataupun mengatur ulang pengeluaran proyek demi terjaganya kelangsungan proyek.

\section{DAFTAR PUSTAKA}

Aal, A. E. 1995. Couse Of Delay In Large Building Construction Project. Teknik Sipil. Journal Vol. 5

Budiman Prabowo. 1999. Keterlambatan Waktu Pelaksanaan Dan Peringkat Dari PenyebabPenyebab Untuk Proyek Yang Ada Di Wilayah Surabaya

Dipohusodo, Istimawan. 1996. Manajemen Proyek Dan Konstruksi. Yogyakarta : Kanisius

Ervianto. W. I. 2005 , Teori Aplikasimanajeman Proyek Konstruksi Edisi Revisi, Yogyakarta: Penerbit Andi

Gray, C. F. 2006. Manajemen Proyek, New York: Penerbit Andi

Hartono, Lukman. 2013. Pengaruh Aspek Pelaksanaan Konstruksi Terhadap Kinerja Waktu Proyek. Jawa Tengah; Serviensin Lumine Variatis

Hasan, Iqbal. 2011. Pokok-Pokok Materi Statistik 1 (Statistik Deskriptif). Jakarta: Bumi Aksara

Haekal Hasan. 2016. Faktor-Faktor Penyebab Keterlambatan Pada Proyek Konstruksi Dan Alternative Penyelesaiannya (Studi Kasus: Di Manado Town Square Iii)

Hasaloan Banget Sianipar. (2012). Analisis Factor-Faktor Penyebab Keterlambatan Penyelesaian Proyek Konstruksi Dan Pengaruhnya Terhadap Biaya, Di Wilayah Keresidenan Surakarta

Henong, Sebastianus. 2016. Analisa Faktor-Faktor yang Mempengaruhi Keterlambatan Pada Proyek Pemerintahan Di Kota Kupang. Universitas Katolik Widya Mandira Kupang

I.A. Rai Widhiawati. (2009). Bertujuan Untuk Mengetahui Penyebab Utama Dari Keterlambatan Penyelesaian Proyek Konstruksi Yang Berada Di Kotamadya Denpasar

Lulu, Laurensius. 2004. Manajemen Konstruksi Teknik Sipil, Universitas katolik Widya Mandira Kupang.

Suyanto (2009) Bertujuan Untuk Mengetahui Faktor-Faktor Penyebab Keterlambatan Penyelesaian Proyek Yang Berada Di Kotamadya Surakarta Dan Untuk Mengetahui Peringkat Menurut Presepsi Penyedia Jasa Terhadap Factor-Faktor Penyebab Keterlambatan Penyelesaian Proyek

Usboko Gregorius. 2017. Analisis Faktor-Faktor Penyebab Pekerjaan Ulang (Rework) Pada Pekerjaan Konstruksi Bangunan Gedung Di Kota Kupang. Universitas Katolik Widya Mandira Kupang 